\title{
Pentoxifylline as a new adjunctive therapy in ankylosing spondylitis: A randomized clinical trial
}

\author{
Zahra Zakeri ${ }^{1}$, Ali Davarian ${ }^{2,3 *}$, Seyed Amirhossein Fazeli ${ }^{4}$, Mahnaz Sandoughi ${ }^{4}$, Sogol Shahbakhsh ${ }^{5}$, Yas \\ Shahbakhsh $^{6}$ and Farzaneh Barzkar ${ }^{7}$ \\ ${ }^{1}$ Department of Internal Medicine, Shahidbeheshti University of Medical Sciences, Tehran, Iran. ${ }^{2}$ Ischemic Disorders Research \\ Center, Golestan University of Medical sciences, Gorgan, Iran. ${ }^{3}$ Department of Internal Medicine, Semnan University of Medical \\ Sciences, Semnan, Iran. ${ }^{4}$ Department of Internal Medicine, School of Medicine, Zahedan University of Medical Sciences, Zahedan, \\ Iran. ${ }^{5}$ Medical Student, Tehran University of Medical Sciences, Tehran, Iran. ${ }^{6}$ Medical Student, Iran University of Medical sciences, \\ Tehran, Iran. ${ }^{7}$ Student Research Center, Zahedan University of Medical Sciences, Zahedan, Iran
}

\begin{abstract}
Treatment with tumor necrosis factor alpha inhibitors has been increasingly implicated in the management of autoimmune diseases. In spite of their promising effects, they are commonly associated with side effects. This issue indicates the need for newer drugs with the same efficacy and fewer serious adverse effects. Pentoxifylline is a phosphodiesterase which inhibits TNF secretion and exerts to some degree an anti-inflammatory effect. The purpose of this randomized clinical trial was to evaluate the effect of pentoxifylline as an adjunctive therapy in the management of ankylosing spondylitis. Twenty-five patients suffering from ankylosing spondylitis were randomly assigned to treatment or placebo groups having been matched for age and gender. The treatment group received pentoxifylline (1200 $\mathrm{mg}$ daily), and the placebo group received a placebo in addition to the standard treatment of sulfasalazine 2-3 gram daily and indomethacin 50-75 $\mathrm{mg}$ per day that were given to all the patients in both groups. Serum levels of TNF- $\alpha$ were measured before and after the study intervention. Serum levels of TNF- $\alpha$ were reduced significantly in both groups with a p-value of $<0.001$. However, the reduction was more prominent in the group receiving pentoxifylline than in the placebo group, although this between-group difference was not statistically significant. The results demonstrate the need for further studies on the use of pentoxifylline as a safe adjunctive therapy in controlling disease activity and reducing tumor necrosis factor-alpha levels in patients with ankylosing spondylitis.
\end{abstract}

Keywords: ankylosing spondylitis, NSAIDs, pentoxifylline, spondyloarthritis, TNF- $\alpha$

\section{Introduction}

Ankylosing Spondylitis (AS) is a chronic inflammatory disease with an unknown etiology that mostly affects the sacroiliac joints and spine and, less commonly, the peripheral joints. It typically presents with low-back pain and gradually progresses to stiffness and fusion of the vertebrae, and it creates a great economic and social burden $[1,2]$.

An effective treatment for AS should control symptoms, decrease structural damage, and improve the patient's quality of life. Non-steroidal anti-inflammatory drugs (NSAID) are known as first-line drugs for the management of this condition [3]. In patients with peripheral arthritis, disease-modifying anti-rheumatic drugs (DMARD) such as sulfasalazine could also be considered as well as intra-articular injections of glucocorticoids [4]. However, there is no evidence to support the administration of these drugs in patients with axial spondyloarthritis.

Recent studies have suggested the use of anti-tumor necrosis factor (anti-TNF) agents as another option for patients with elevated disease activity, especially for axial arthritis [5, 6]. Infliximab, etanercept, adalimumab, golimumab, and certolizumab are antiTNF agents that have been used successfully in the treatment of AS in recent years [6-9]. On the other hand, inhibition of TNF- $\alpha$ with the monoclonal antibody infliximab [10] or the soluble TNF receptor etanercept has resulted in increased mortality and is associated with many side effects [11]. Consequently, it is necessary to find some other medications with antiTNF- $\alpha$ properties and less serious side effects.

Pentoxifylline, an oral anti-TNF agent that inhibits

* Corresponding Author: Ali Davarian, Email: alidavarian @ gmail.com, Tel: +98 9113710978

Received: 11 December 2016; Accepted: 01 March 2017 
phosphodiesterase [12], has been shown to be useful in decreasing serum levels of TNF- $\alpha$ in many disease conditions with an inflammatory pathogenesis, including AIDS [13], acute lung injury [14], alcoholic and non-alcoholic steatohepatitis [15], and refractory nephrotic syndrome secondary to lupus nephritis [16]. Some studies have found that pentoxifylline is effective in the treatment of patients with rheumatoid arthritis [17-19]. However, there is no study on the role of pentoxifylline in the treatment of patients with AS. Therefore, the current study was designed to evaluate the role of pentoxifylline as an adjunctive therapy in slowing disease progression in patients with ankylosing spondylitis.

\section{Patients and Methods}

This randomized clinical trial was conducted on patients with active ankylosing spondylitis (AS) who referred to the Rheumatology Clinic at Ali-ebne-Abitaleb Hospital, Zahedan, Iran. The diagnosis was confirmed by a rheumatologist using the Modified New York Criteria for AS. All patients with no history of receiving anti TNF- $\alpha$ drugs were included to the study. Any patients with an infection, history of central nervous system bleeding or coagulopathy, or drug reaction during the period of study were excluded from the study.

Patients were informed about the study and told they had the right to leave the trial at any time during the study. After informed consent was obtained from each patient, a thorough medical history was taken and a complete physical examination was performed. The trial design and all ethical issues concerning the patients were confirmed by the Ethics Committee of Zahedan University of Medical Sciences. Disease activity was evaluated based on BASDAI (Bath Ankylosing Spondylitis Disease Activity Index). Disease duration, type, and duration of previous treatments were determined and recorded. Blood samples were taken to measure serum levels of TNF- $\alpha$ by the ELISA method, ESR, and CRP as a determinant factor of baseline disease activity before intervention. After matching for age, gender, and average disease activity, 25 patients were randomly assigned to treatment $(n=12)$ and placebo $(n=13)$ groups using the random classified blocking method. The duration of study was 12 weeks. Patients of both groups received similar standard treatments for AS, including sulfasalazine 2-3 g per day and indomethacin $50-75 \mathrm{mg}$ per day. In case of failure to respond to sulfasalazine during the study, $10 \mathrm{mg}$ of weekly methotrexate was added to the treatment regimen for both groups.
The treatment group received pentoxifylline (1200 mg daily) as an adjunct to the standard treatment in divided doses (400 mg TDS for 12 weeks), while patients of the placebo group received a placebo in addition to the routine regimen. Blinding was performed according to random classified blocking methods. Doses of all of the drugs received by the patients were documented precisely in the beginning, during, and at the end of the study, and any changes in doses were noted. Symptoms associated with serious side effects, including bleeding, were described for the patients, and they were asked to refer immediately to an emergency department in case of experiencing such symptoms. During treatment, patients were visited periodically and monitored for drug side effects. Twelve weeks after the trial was initiated, another complete physical exam was conducted and blood specimens were taken for the measurement of serum levels of TNF- $\alpha$, ESR, CRP and the determination of disease activity using BASDAI. All samples were transferred to measure the serum level of TNF- $\alpha$ all at once and measurements were performed using the same brand of laboratory kits before and after intervention. This strategy was considered to minimize measurement bias. Changes in ESR and CRP were assessed after 12 weeks of follow-up in all patients.

\section{Statistical analysis}

All data was analyzed using STATA 10 software. The normality of the BASDAI scores and the serum levels of TNF- $\alpha$ were examined with the Shapiro-Wilk test. In case of normality of data, all comparisons were performed by parametric tests, i.e. $\mathrm{t}$-test and paired $\mathrm{t}$ test. In case the data was not distributed normally, nonparametric tests including the Wilcoxon Signed Ranks Test were used to evaluate changes in ESR and CRP. A p-value of 0.05 was considered significant.

\section{Results}

Twenty-five patients with the diagnosis of ankylosing spondylitis participated in this study and were randomly divided into treatment $(n=12)$ and placebo $(n=13)$ groups. Serum TNF- $\alpha$ levels of one patient in the placebo group were very high and differed significantly from that of the other patients. In order to prevent bias in analyzing, that data was omitted. Two individuals in the placebo group left the trial because of a lack of interest in continuing the study protocol. All data related to those two individuals was also omitted from statistical analyses. Data from the 10 individuals remaining in the placebo group were analyzed.

During the study period, pentoxifylline was well 
Zakeri et al.

tolerated by patients. None of the patients in the treatment or placebo group complained of any symptoms indicating allergies or other drug side effects.

There was no significant difference in BASDAI scores between the treatment and placebo groups before intervention $(\mathrm{P}=0.12)$. The mean BASDAI scores in both groups were significantly lower after the trial $(\mathrm{P}<0.001)$; however, the decrease of the score in the treatment group following the trial was more prominent. Moreover, the mean level of this score was significantly lower in the treatment group after trial than in the placebo group $(\mathrm{P}=0.004)$.

Results of the current study indicated no significant baseline difference in the median amounts of serum levels of TNF- $\alpha$ between treatment and placebo groups $(\mathrm{P}=0.151)$. The levels of TNF- $\alpha$ significantly decreased after intervention in both groups $(\mathrm{P}<0.01)$. This decrement was more prominent in the treatment group in comparison with the placebo group, although this prominence was not statistically significant $(\mathrm{P}=0.091)$. The level of TNF- $\alpha$ was significantly lower in the treatment group than in the placebo group after intervention (0.016). The serum levels of ESR and CRP was not significantly different after 12 weeks of treatment in the placebo group. ESR decreased $5 \mathrm{~mm} / \mathrm{hr}$ $(\mathrm{P}=0.25)$, and CRP decreased $1.70 \mathrm{mg} / \mathrm{l} \quad(\mathrm{P}=0.72)$. However, in the treatment group, the reductions in ESR and CRP serum levels were significant. ESR decreased $37.10 \mathrm{~mm} / \mathrm{hr}(\mathrm{P}=0.01)$, and CRP decreased $16.00 \mathrm{mg} / \mathrm{l}$ $(\mathrm{P}=0.02)$.

Table 1. BASDAI scores of treatment and placebo groups at the beginning and at the end of the study protocol

\begin{tabular}{|c|c|c|c|c|}
\hline 产 & 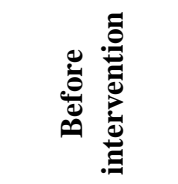 & 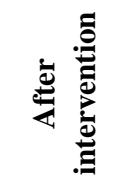 & 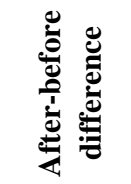 & 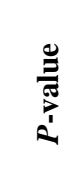 \\
\hline $\begin{array}{l}\text { eatment } \\
\text { dian; IR*) }\end{array}$ & $46.65 ; 62.95$ & $\begin{array}{l}19.55 \\
36.78\end{array}$ & $\begin{array}{c}-26.20 \\
26.52\end{array}$ & 0.002 \\
\hline $5 \% \mathrm{CI}$ & $\begin{array}{c}(21.96- \\
87.81)\end{array}$ & $\begin{array}{c}(11.10- \\
49.72)\end{array}$ & $\begin{array}{c}(-38.71- \\
-12.03)\end{array}$ & \\
\hline $\begin{array}{l}\text { lacebo } \\
\text { dian; IR) }\end{array}$ & $\begin{array}{c}104.00 \\
85.90\end{array}$ & $\begin{array}{l}89.00 \\
75.30\end{array}$ & $\begin{array}{l}12.50 \\
18.50-\end{array}$ & 0.003 \\
\hline -value & 0.151 & 0.016 & 0.091 & \\
\hline
\end{tabular}

Table 2. Serum levels of TNF- $\alpha$ of treatment and placebo groups at the beginning and at the end of the study protocol

\begin{tabular}{cccc}
\hline Group & $\begin{array}{c}\text { Before } \\
\text { intervention }\end{array}$ & $\begin{array}{c}\text { After } \\
\text { intervention }\end{array}$ & $\boldsymbol{P}$-value \\
\hline $\begin{array}{c}\text { Treatment } \\
(\text { mean } \pm \text { SD })\end{array}$ & $4.58 \pm 0.83$ & $2.36 \pm 0.48$ & $<0.001$ \\
$(95 \% \mathrm{CI})$ & $(4.05-5.11)$ & $(2.05-2.66)$ & \\
$\begin{array}{c}\text { Placebo } \\
(\text { mean } \pm \text { SD })\end{array}$ & $3.95 \pm 1.04$ & $3.25 \pm 0.81$ & 0.001 \\
$(95 \% \mathrm{CI})$ & $(3.25-4.65)$ & $(2.71-3.80)$ & \\
\hline
\end{tabular}

IR: Interquartile range

\section{Discussion}

The mainstay of treatment for ankylosing spondylitis is currently based on a combination of education, exercise, physical therapy, rehabilitation, patient associations, self-help groups, and pharmacotherapy which is aimed at improving joint pain and function, and consequently enhancing the quality of life. NSAIDs are the first-line pharmacological agents used in the management of this condition in combination with intra-articular corticosteroids and sulfasalazine and other DMARDs with more prominent peripheral features. However, antitumor necrosis factor- $\alpha$ (TNF- $\alpha$ ) drugs have been shown to have promising outcomes regarding their impact on joint pain and function [20].

This randomized clinical trial demonstrated the considerable benefit of pentoxifylline as an add-on therapy in the treatment of ankylosing spondylitis (AS). The BASDAI scores reflecting the level of disease activity in the patients improved significantly following treatment with pentoxifylline. In addition, significantly lower levels of TNF- $\alpha$ were seen in patients treated with pentoxifylline compared to the placebo individuals. TNF blockers have shown significant efficacy in symptomatic relief and improvement of quality of life among AS patients; however, these agents have not been associated with decreased radiographic progression of disease. Despite the significant role of TNF blockade in preventing erosive bone damage in RA and psoriatic arthritis, new bone formation, which is the mainstay of radiologic findings in AS, has not been shown to be suppressed by TNF blockers [5, 6, 21, 22].

Given the possible role of TNF- $\alpha$ in the pathogenesis of many inflammatory disorders, TNF blockade has been increasingly proposed for the treatment of such disorders in recent years [23].

Nevertheless, the wide variety of roles TNF plays makes the use of these biologic agents a concerning issue, as their impact is not limited to the role of TNF in the pathologic process, but also alters the physiologic roles of this important agent causing a significant range 
of side effects. One such effect is its important role in the mediation of $\mathrm{TH} 1$ response to intracellular bacteria and viruses which is an especially important mechanism in limiting infectious pathogens like mycobacterium tuberculosis [23].

After more than a decade of developing TNF blockers, their safety profiles have been largely revealed. Opportunistic infections such as those caused by Listeria, Cryptococcus, Pneumocystis, and Aspergillus as well as Mycobacterium tuberculosis have been described. Risks of the reactivation of Hepatitis B and latent tuberculosis (TB) and the exacerbation of Hepatitis $\mathrm{C}$ have also been associated with the use of infliximab. Among these, tuberculosis reactivation is especially significant in TB-prevalent areas as applies to the southeast of Iran. In addition to infectious adverse effects, cholecystitis, gall stones, non-infectious hepatitis, and jaundice have also been mentioned. The increased risk of malignancies such as lymphoma and cutaneous malignancies is another safety concern of TNF blockers [24]. Furthermore, a lupus-like syndrome has been reported following treatment with infliximab. Seizure, optic neuritis, and multiple sclerosis are among the neurologic disorders associated with the use of TNF blockers. Despite some proposed benefits of TNF blockers in congestive heart failure, it is known that TNF blockers can worsen a patient's underlying heart condition, especially in the elderly [24, 25]. In addition to the mentioned clinical consequences of biologic antiTNF agents, there are other pitfalls that complicate the use of these drugs. Among these, one important aspect is their cost which is especially significant for patients of the lower socioeconomic classes and may result in non-compliance. Other economic issues associated with the use of biologic anti-TNF agents are imposed by the costs of their adverse effects. According to the available data, none of the current anti-TNF agents appear to be cost-effective for the management of AS with infliximab showing the poorest results in short-term models [21].

Pentoxifylline, however, is a phosphodiesterase inhibitor which has anti-TNF $\alpha$ properties with many advantages over biologic agents such as infliximab. The side effects described for pentoxifylline are very limited, presenting it as a safer medication. No severe infections have been reported following the administration of this drug. Furthermore, pentoxifylline is not expensive and is available to all patients of different socio-economic classes. Pentoxifylline is not only compatible with other drugs used for the management of AS, but it is also postulated to act synergistically to reduce $\mathrm{TNF}-\alpha$ levels through independent mechanisms with sulfasalazine. Their effectiveness has been shown in other autoimmune disorders such as pemphigus vulgaris, entero-Behcet's disease, and psoriasis [26-28]. This is particularly important in the geographical area where the authors of the current study practice because of the higher prevalence of infectious diseases such as TB and the relatively lower socioeconomic status of the population, both of which make the prescription of anti-TNF agents an even more challenging issue and the search for alternatives a necessary area of research. The results of this trial suggest that drugs like pentoxifylline are effective in reducing disease activity among patients with progressive ankylosing spondylitis. The authors recommend further clinical trials that compare the effects of pentoxifylline with biologic agents such as infliximab, etanercept, or adalimumab on reducing disease activity and improving the quality of life of AS patients, to further assess the usefulness and effects of the drug in clinical practice, and to determine whether this drug can be considered for addition to the list of routine drugs used in line with or as an alternative agent to biologic anti-TNF agents in the management of AS. It also recommended that long-term studies on a higher number of patients and with different doses of pentoxifylline be conducted to discover the most efficient doses. The BASDAI scoring system was used in this trial to evaluate disease activity; more measurable indices are recommended for the evaluation of disease activity in future trials so as to improve the fidelity of the results.

\section{Conclusion}

According to the results of this study, the vast variety of side effects mentioned for anti-TNF- $\alpha$ agents indicate the need for research on the efficacy of drugs like pentoxifylline with similar activity and fewer side effects as an adjunctive therapy in the management of patients with ankylosing spondylitis

\section{Conflict of interest}

The authors declare no conflicts of interest.

\section{References}

$\begin{array}{llll}\begin{array}{l}\text { 1. Braun J, Sieper J. Ankylosing } \\ \text { spondylitis. 2. Lancet 2007; }\end{array} & \begin{array}{l}\text { Boonen A, Chorus A, Miedema } \\ \text { H, van der Heijde D, van der }\end{array} & \begin{array}{l}\text { Employment, work disability, and } \\ \text { work days lost in patients with } \\ \text { 369(9570): 1379-90. }\end{array} \\ \text { ankylosing spondylitis: a cross }\end{array}$


sectional study of Dutch patients. Ann Rheum Dis 2001; 60(4): 353-8. doi:10.1136/ard.60.4.353.

3. Peterson $\mathrm{K}$, McDonagh $\mathrm{M}$, Thakurta S, Dana T, Roberts C, Chou R. et al. Drug Class Review: Nonsteroidal Antiinflammatory Drugs (NSAIDs): Final Update 4 Report [Internet].

4. Steiman AJ, Pope JE, ThiessenPhilbrook H, Li L, Barnabe C, Kalache F. et al. Non-biologic disease-modifying antirheumatic drugs (DMARDs) improve pain in inflammatory arthritis (IA): a systematic literature review of randomized controlled trials. Rheumatol Int 2013; 33(5): 1105-20. doi: 10.1007/s00296012-2619-6.

5. van der Heijde D, Sieper J, Maksymowych WP, Dougados M, Burgos-Vargas R, Landewe R. et al. 2010 update of the international ASAS recommendations for the use of anti-TNF agents in patients with axial spondyloarthritis. Ann Rheum Dis 2011; 70(6): 905-8. doi: 10.1136/ard.2011.151563.

6. Machado MA, Barbosa MM, Almeida AM, de Araujo VE, Kakehasi AM, Andrade EI. et al. Treatment of ankylosing spondylitis with TNF blockers: a meta-analysis. Rheumatol Int 2013; 33(9): 2199-213. doi: 10. 1007/s00296-013-2772-6.

7. Braun J, Brandt J, Listing J, Zink A, Alten R, Burmester G. et al. Long-term efficacy and safety of infliximab in the treatment of ankylosing spondylitis: an open, observational, extension study of a three-month, randomized, placebo-controlled trial. Arthritis Rheum 2003; 48(8): 2224-33. doi: 10.1002/art.11104

8. Davis JC, Jr., Revicki D, van der Heijde DM, Rentz AM, Wong RL, Kupper H. et al. Healthrelated quality of life outcomes in patients with active ankylosing spondylitis treated with adalimumab: results from a randomized controlled study. Arthritis Rheum 2007; 57(6): 1050-7.

9. Brandt J, Khariouzov A, Listing $J$, Haibel $H$, Sorensen $H$, Grassnickel L. et al. Six-month results of a double-blind, placebo- controlled trial of etanercept treatment in patients with active ankylosing spondylitis. Arthritis Rheum 2003; 48(6): 1667-75. doi:10.1002/art.11017.

10. Naveau $S$, Chollet-Martin S, Dharancy S, Mathurin P, Jouet P, Piquet MA. et al. A double-blind randomized controlled trial of infliximab associated with prednisolone in acute alcoholic hepatitis. Hepatology 2004; 39(5): 1390-7. doi: 10.1002/hep. 20206.

11. Boetticher NC, Peine CJ, Kwo P, Abrams GA, Patel T, Aqel B. et al. A randomized, double-blinded, placebo-controlled multicenter trial of etanercept in the treatment of alcoholic hepatitis. Gastroenterology 2008; 135(6): 1953-60. doi: 10.1053/j.gastro. 2008.08.057

12. Semmler J, Gebert U, Eisenhut T, Moeller J, Schonharting MM, Allera A. et al. Xanthine derivatives: comparison between suppression of tumour necrosis factor-alpha production and inhibition of cAMP phosphodiesterase activity. Immunology 1993; 78(4): 520-5.

13. Wanchu A, Bhatnagar A, Bambery P, Singh S, Varma S. Prevention of opportunistic infections in HIV infection by pentoxiphylline. Indian $\mathbf{J}$ Med Res 2006; 124(6): 705-8.

14. Konrad FM, Neudeck G, Vollmer I, Ngamsri KC, Thiel M, Reutershan J. Protective effects of pentoxifylline in pulmonary inflammation are adenosine receptor A2A dependent. Faseb J 2013; 27(9): 3524-35. doi: 10. 1096/fj.13-228122.

15. Perri RE, Shah VH. Pentoxifylline: not just for alcoholic hepatitis anymore? Hepatol Int 2008; 2(2): 137-9. doi: 10.1007/s12072-008-9057-2.

16. Galindo-Rodriguez G, Bustamante R, Esquivel-Nava G, Salazar-Exaire D, Vela-Ojeda J, Vadillo-Buenfil M. et al. Pentoxifylline in the treatment of refractory nephrotic syndrome secondary to lupus nephritis. $\boldsymbol{J}$ Rheumatol 2003; 30(11): 2382-4.

17. Ishii $\mathrm{O}$, Yamada $\mathrm{H}$, Ohya $\mathrm{S}$, Moriuchi E, Kase C, Ichikawa Y. et al. Remission induction after pentoxifylline treatment in a patient with rheumatoid arthritis. Ryumachi 1997; 37(6): 810-5.

18. Dubost JJ, Soubrier M, Ristori JM, Beaujon G, Oualid T, Bussiere JL. et al. An open study of the anti-TNF alpha agent pentoxifylline in the treatment of rheumatoid arthritis. Rev Rhum Engl Ed 1997; 64(12): 789-93.

19. Huizinga TW, Dijkmans BA, van der Velde EA, van de Pouw Kraan TC, Verweij CL, Breedveld FC. An open study of pentoxyfylline and thalidomide as adjuvant therapy in the treatment of rheumatoid arthritis. Ann Rheum Dis 1996; 55(11): 833-6. doi: 10.1136/ard.55.11.833.

20. Braun $J$, van den Berg $R$, Baraliakos X, Boehm H, BurgosVargas R, Collantes-Estevez E. et al. 2010 update of the ASAS/EULAR recommendations for the management of ankylosing spondylitis. Annals of the Rheumatic Diseases 2011; 70(6): 896-904. doi: 10.1136/ard.2011. 151027.

21. McLeod C, Bagust A, Boland A, Dagenais P, Dickson R, Dundar Y. et al. Adalimumab, etanercept and infliximab for the treatment of ankylosing spondylitis: a systematic review and economic evaluation. Health Technol Assess 2007; 11(28): 1-158, iii-iv. doi: $10.3310 /$ hta11280.

22. Reed MR, Taylor AL. Tumour necrosis factor inhibitors in ankylosing spondylitis. Intern Med J 2008; 38(10): 781-9. doi: 10.1111/j.1445-5994.2008.01639. $\mathrm{x}$.

23. Blandizzi $\mathrm{C}$, Gionchetti $\mathrm{P}$, Armuzzi A, Caporali R, Chimenti $\mathrm{S}$, Cimaz R. et al. The role of tumour necrosis factor in the pathogenesis of immunemediated diseases. Int $J$ Immunopathol Pharmacol 2014; 27 (1 Suppl): 1-10. doi: 10.1177/03946320140270s101.

24. Jain A, Singh JA. Harms of TNF inhibitors in rheumatic diseases: a focused review of the literature. Immunotherapy 2013; 5(3): 265 99. doi: 10.2217/imt.13.10.

25. Silva LC, Ortigosa LC, Benard G. Anti-TNF-alpha agents in the treatment of immune-mediated inflammatory diseases: mechanisms of action and pitfalls. Immunotherapy 2010; 2(6):817- 
Ankylosing spondylitis with pentoxifylline

33. doi: 10.2217/imt.10.67.

26. el-Darouti M, Marzouk S, Abdel

Hay R, el-Tawdy A, Fawzy M,

Leheta $T$. et al. The use of sulfasalazine and pentoxifylline (low-cost antitumour necrosis factor drugs) as adjuvant therapy for the treatment of pemphigus vulgaris: a comparative study. $\boldsymbol{B r}$ J Dermatol 2009; 161(2): 313-9. doi: $\quad 10.1111 / \mathrm{j} .1365-2133.2009$. 09208.x.

27. el-Mofty M, el-Darouti M, Rasheed H, Bassiouny DA Abdel-Halim M, Zaki NS. et al. Sulfasalazine and pentoxifylline in psoriasis: a possible safe alternative. J Dermatolog Treat 2011; 22(1): 31-7. doi: 10.3109/ 09546630903460260 .
28. Hisamatsu $\mathrm{T}$, Kishikawa $\mathrm{H}$, Fukuya H, Matsuoka K, Mizuno Y, Nishida J. Combination therapy including pentoxifylline for entero-Behcet's disease. Bull Tokyo Dent Coll 2001; 42(3): 169-76. doi: 10.2209/ tdcpublication.42.169. 